\title{
Urban Chinese Social Organization: Some Unexplored Aspects in Huiguan Development in Singapore, I900-194I
}

WING CHUNG NG

University of British Columbia

\section{Introduction}

Immigrant associations known commonly as huiguan have long been a research area among specialists on the Overseas Chinese. ${ }^{1}$ Recently, the same subject has attracted increasing attention among scholars who attempt to examine urban life in late imperial China. ${ }^{2}$ In either case, the existing historical literature seems to have focused on the two following aspects of huiguan development: the various principles of organizational formation such as common native place, surname,

This is a revised version of a paper presented at the annual meeting of Asian Studies on the Pacific Coast, Stanford University, 29 June - I July, r9go. I would like to thank Mary Turnbull, Edgar Wickberg, W. E. Cheong, Ming Chan, Tay Lian Soo and Hamashita Takeshi for their advice and support in this research. In addition, I want to extend my gratitude to the Chinese social organizations in Singapore which gave me access to their archival materials.

1 A bibliographical essay would be needed to appreciate the breadth and depth of the existing literature on this topic. Specific works aside, many studies on the ethnic Chinese abroad have shed light on it. Nevertheless the loci classici are G. W. Skinner, Leadership and Power in the Chinese Community in Thailand (Ithaca, 1958) and M. Freedman, 'Immigrants and Association: Chinese in Nineteenth-Century Singapore', Comparative Studies in Society and History 3 ( $1960-196 \mathrm{r}), 25-48$.

${ }^{2}$ Compared with what we have on the overseas Chinese, the size of the literature on the huiguan in urban China is more modest but is still considerable. Again I would confine myself to the loci classici: Dou Jiliang, Tongxiang zuzhi zhi yanjiu (Studies on Native Place Organizations) (Chongqing, I 943); Ho Ping Ti, Zhongguo huiguan shilun (An Historical Survey of Landsmannschaften in China) (Taipei, 1966); the relevant essays in Skinner (ed.), The City in Late Imperial China (Stanford, 1977); W. T. Rowe, Hankow: Commerce and Society in a Chinese City 1796-1889 (Stanford, 1984), and Hankow: Confict and Community in a Chinese City 1796-1895 (Stanford, 1989). Note also the important studies by Japanèse scholars such as Negishi Tadashi, Kato Shigeshi, Niida Noboru and Imahori Seiji on Chinese society in general and guild organizations in particular. 
occupation and the new locational identity, and how they interacted with one another and shaped the community structure; the functional relevance of huiguan firstly to the various needs of the immigrant society and the local elite, and secondly to the overriding concerns of the ruling authority, be it the Chinese imperial bureaucracy or the governing authorities in a foreign settlement. Yet few attempts have been made to delineate the longitudinal evolution of these associations over an extended period in any single locale, and above all, to provide an analytical framework to decipher the complex interplay of different forces behind organizational changes. Relying primarily on Chinese newspapers, huiguan archives and publications in Singapore, ${ }^{3}$ this paper represents a very preliminary effort along both lines. After a brief background discussion on the nineteenth century, I will try to document closely several significant features in the development of Chinese huiguan in Singapore between the turn of the century and the beginning of the Pacific War. The main thrust here is to demonstrate the possibility of going beyond number games, that pay too much attention to organizational inventory, to examine more substantive issues such as changes in organizational forms, the revamping of institutional set-ups, leadership turnover and varying functional priorities. Then the following section will seek to account for these organizational metamorphoses. It will be argued that our explanatory paradigm should at least consist of three categories of factors: domestic forces associated with community evolution; the impact of the host society; and influences emanating from China and particularly the native area.

Hopefully, this exercise would not just add another set of empirical information for the study of ethnic Chinese abroad. While I have not

3 In the course of this study, three major local Chinese newspapers have been scrutinized. They are the Lat Pau (1912-1919), the Nanyang Siang Pau (1923-1941) and the Sin Chew Jit Poh (1929-194I). In subsequent references, they will be rendered as LP, NYSP and SCJP respectively. As for the huiguan archival materials, I have used extensively the collections of the Singapore National Archives and those made available to me by individual associations. Chinese social organizations were first encouraged to deposit their historical records at the National Archives in the early I970s and the repository has been growing since then. Materials extracted from it will be indicated by an ' $N A$ ' followed by the file specification. Last but not least, over seventy volumes of huiguan publications, mainly in the form of souvenir magazines, have been examined. The Singapore National Library, the University Libraries of the National University of Singapore and the University of Malaya all have significant holdings. For bibliographical aid, see Tay Lian Soo, Xinma huazu shiliao wenxian huimu (Classified Bibliography of Chinese Historical Materials in Malaysia and Singapore) (Singapore, 1984), and Lim How Seng, Singapore Chinese Huiguan Publications: A Bibliography (Singapore, 1989). 
espoused any particular theory, my findings might have some theoretical implications for our understanding of organizational dynamics and community change among the overseas Chinese. By extension, it may also shed light on the study of urban social organizations in China proper. The brief comparative discourse at the end of this paper is heading towards such a dialogue.

\section{Huiguan and Society in the Nineteenth Century: A Historical Background}

Though our study begins with the turn of the century, the history of Chinese huiguan in Singapore can be traced back to the founding of the island community by the British in 1819 . It is widely believed that the first Chinese social organization was a surname association called Cho Kah Koon. ${ }^{4}$ It was formed among some Chinese recruits in the pioneering British company. ${ }^{5}$ As the Chinese continued to settle on the island from some neighbouring settlements and also directly from the two coastal provinces of Fujian and Guangdong, so did the number of their organizations multiply. The Chinese population reached its first 10,000 in the mid-183os and increased some ten-fold in the following half century. Equally spectacular was the rapid associational proliferation, so that by the end of the century there were more than $5^{\circ}$ Chinese social organizations, including a roughly equal number of dialect group temples, native place institutions, clan associations, and a smaller number of commercial and craft guilds. ${ }^{6}$

Two things should be noted before we proceed to our narrative on the twentieth century. First, the early Chinese immigrants established

4 In rendering romanized names, I incline to respect local usages. Only when the original names of the organizations or the individuals in English form are not known, then I use pinyin as the general rule. The latter also applies to place names in China.

${ }^{5}$ For a highly romantic version of the episode, see the account given in Ngow Hua, Xinjiapo huazu huiguan zhi (A General History of Ethnic Chinese Associations in Singapore) vol. 2 (Singapore, 1975), 2-3.

${ }_{6}$ The population data are from Lee Poh Ping, Chinese Society in Nineteenth Century Singapore (Kuala Lumpur, 1978), 38, and Saw Swee Hock, Singapore Population in Transition (Philadelphia, 1970), 57. The principal sources of information on huiguan demography are as follows: Cheng Lim-keak, Social Change and the Chinese in Singapore-A Socio-economic Geography with Special Reference to Bang Structure (Singapore, 1985); Lim How Seng, Shile guji (Monuments of Singapore) (Singapore, 1975); W. Moese et al., Chinese Regionalism in West Malaysia and Singapore (Hamburg, 1979); Ngow Hua, Xinjiapo huazu huiguan zhi, 3 vols; Yen Ching-hwang, A Social History of the Chinese in Singapore and Malaya 1800-1911 (Singapore, 1986); and the numerous huiguan publications. 
different types of huiguan primarily for self-help and protection. In an alien environment, the huiguan in their various forms were to afford the settlers a secure anchorage in more familiar cultural and social settings. Almost every organization at that time had a strong emphasis on ritual solidarity centred around the worshipping of popular deities that originated either from Southeastern China or locally in Southeast Asia. ${ }^{7}$ Moreover, the huiguan were places where one could meet with fellow regionals and clansmen, exchange business and job information, share news from the native area, and engage in a meaningful social life. Many of them were involved in different kinds of welfare and charity: they might provide board and lodging for the new arrivals and the destitute; a few of them could afford a free ship ticket back to China for those who were poor and old; and most would promise their members a proper funeral and burial after untimely death. $^{8}$

Beyond a personal level of support and service, the development of huiguan had greater social significance. With few exceptions, all the Chinese huiguan can be divided into dialect group categories which were called bang in the Nanyang. Bang can be taken as the principal associational rule and other regional, surname and occupational affiliations served largely for further segmentation. ${ }^{9}$ By the mid-nineteenth

7 The Sea Goddess and the Ta Po Kung were respective examples. For an informed discussion on popular religion among the Chinese in Singapore, see Moese et al., Chinese Regionalism, 348ff. Also relevant is E. Lip, Chinese Temple Architecture in Singapore (Singapore, $19^{8} 3$ ).

8 Regarding the local functions of the huiguan, the best discussion to date is Yen Ching-hwang, $A$ Social History of the Chinese. For an anthropological perspective, see Hsieh Jiann, 'Internal Structure and Socio-cultural Change: A Chinese Case in the Multi-Ethnic Society of Singapore', Ph.D. dissertation, University of Pittsburgh, 1977 .

${ }_{9}$ Bang was an extremely dynamic phenomenon discernible in Chinese society both at home and abroad. Depending on the unique sub-ethnic composition of the local community, a bang can denote the collective identity and socio-economic existence of a group of migrant traders and/or labourers. Members of a bang came from a defined territory which might include the entire or a part of a macroregion, a single province, or various mixtures of prefectures and districts. Japanese scholars have studied this topic quite extensively (see note 2). Among western scholars, see Susan Mann Jones, 'The Ningpo Pang and Financial Power at Shanghai', M. Elvin and W. Skinner (eds), The Chinese City between two Worlds (Stanford, 1974), 73-96, and Rowe, Hankow: Commerce and Society, 254-76 passim. For some general discussions on bang overseas, see Chen Guchuan, 'Huaqiao yu diyu guannian', (Overseas Chinese and Regional Identity) Nanyang Yanjiu 2 (10.1928), 19-29; Wu Zhuhui, Huaqiao banzhi de fenxi (An Analysis of the Nature of the Overseas Chinese) (Taipei, 1983), I I 2-31. The following references are on the Chinese in Singapore and Malaya specifically: Mak Lau Fong, Fangyanqun rentong: zaogi xinma huaren de fenlei faze (Dialect Group Identity: A Study of Chinese Sub-ethnic Groups in early Malaya and Singapore) (Taipei, 1985); 
century, the five major Chinese dialect groups in Singapore had established some kind of bang headquarters to represent their respective interests in the eyes of the colonial administration and in popular consciousness. The Hokkiens, who were the most powerful group in terms of population size and financial strength, had their Thian Hock Keng built in 1839 . The elaborate temple structure and internal decoration together with the initiation rituals reportedly cost some 36, ooo Mexican dollars. ${ }^{10}$ The Teochew bang centre was originally in the Wak Hai Cheng Bio but was later transferred to the Ngee Ann Kongsi which was founded in 1845 by thirteen elite families from the Chaozhou districts of Chaoan and Chenghai. ${ }^{11}$ The bang temples of the less affluent Hakkas and Cantonese were both known as Fuk Tak Chi and that of the Hainanese as Kiung Chow Tin Hou Kong. ${ }^{12}$ These organizations were all seriously regarded as symbols of collective identities and loci of bang power. Within each sub-ethnic group, the lesser huiguan, clan associations and guilds seldom developed a formal relationship of subordination with the bang centre. Yet there was considerable overlapping in huiguan leadership so that the management committees of the leading organizations were nexus of personal networks, and thereby of enormous influence and authority. ${ }^{13}$ Moreover, the crystallization of a bang society is also discernible in community-wide organizations. When the Thong Chai Hospital was founded in 1867 to provide free medical care for the

Taku Suyama, 'Pang Societies and the Economy of Chinese Immigrants: A Study on Communalism in Southeast Asia', K. G. Tregonning (ed.), Papers on Malayan History (Singapore, 1962), 193-213; and Yong Ching-fatt, 'Pang, Pang Organizations and Leadership in the Chinese Community of Singapore during the r93os', Journal of the South Seas Society 32 ( 1 977), 3 I-52. Also cf. Him Mark Lai, 'Historical Development of the Chinese Consolidated Benevolent Association/Huiguan System', in Chinese America: History and Perspective 1987 (San Francisco, 1987), 13-51.

10 Ngow Hua, Xinjiapo huazu huiguan zhi, vol. 1, 57 and Lee Poh Ping, Chinese Society, $50-1$.

11 Ngow Hua, Xinjiapo huazu huiguan zhi, vol. I, 63 and Lim How Seng, Shile guji, 2 I.

${ }_{12}$ Lip, Chinese Temple Architecture, 62; Fudeci luyeting yuangeshi tekan (A History of the Fuk Tak Chi and Luyeting) (Singapore, I963), 19-20; Xinjiapo giongzhou tianhougong giongzhou huiguan dasha luocheng jinian tekan (Singapore Kiung Chow Tin Hou Kong Kiung Chow Hwee Kuan Building Opening Ceremony Souvenir Magazine) (Singapore, 1965), $65 \mathrm{ff}$.

${ }_{13}$ The most original discussion of this pattern of overlapping directorship and its implication for community leadership is Skinner, Leadership and Power. For the application of his model in other contexts, see Li Yih Yuan, Yige yizhi de shizhen: malaiya huaren shizhen shenghuo diaocha yanjiu (An Immigrant Town: Life in an Overseas Chinese Community in South Malaya) (Taipei, r968), and K. Straaton, 'The Political System of the Vancouver Chinese Community: Associations and Leadership in the Early I96os', Master Thesis, University of British Columbia, 1974 . 
Chinese, it was the first multi-bang enterprise, and its board of directors was made up of an equal number of Guangdong and Fujian representatives who were bang leaders in their own right. ${ }^{14}$ This arrangement became more elaborate and was officially enshrined when the Straits government set up a consultatory Chinese Advisory Board in 1889 in which the five major dialect groups were given separate representation according to the relative size of their population. ${ }^{15}$

\section{Organizational Metamorphoses rgoo-rg4I}

Between I900 and 1941 Chinese huiguan demography underwent numerous changes. The most salient one was probably the sustained expansion in the organizational inventory. My own tabulation from the primary materials and various secondary sources suggests at least a four-fold increase from about 50 organizations to more than 200 by the early i 940 os. Some $40 \%$ of the new bodies were established during the first three decades of the century. There was a lapse in the first half of the r 93 os but it was followed by an unprecedented outburst of enthusiasm for huiguan formation in the succeeding years up to $194 \mathrm{I}$ (see Table r).

The proliferation of social organizations can be perceived in a number of ways. Segmentation, for instance, was occurring at different levels in the sub-ethnic communities. Within the Hokkien bang the natives of Zhangzhou set up their prefectural huiguan in I929 whereas the fellow regionals from Jinjiang, Huian, Anxi, Tongan and Xiamen, all of the Quanzhou prefecture, got organized on a single county basis (see Table 2). The Cantonese further demonstrated that segmentation could take place below the district level. From $193^{\circ}$ to $194^{\text {I }}$, four different sub-district huiguan were formed by the natives from Zhongshan (see Table 3). At the same time surnames and occupations served the purpose of segmentation equally well. For reasons that are still unclear, the Hainanese were particularly eager in developing clan organizations and, indeed, more than half of the new clan bodies were exclusively Hainanese (see Table 4 ). As for guilds, the Hokkiens, Teochews and Cantonese all had contributed a significant number.

14 Tongji yiyuan dasha luocheng jinian tekan (Thong Chai Medical Institution Opening Ceremony Souvenir Magazine) (Singapore, 1979), 7, 104-5, 109-27.

15 Yong Ching-fatt, Zhanqian xinghua shehui jiegou yu lingdaoceng chutan (A Preliminary Study of Chinese Community Structure and Leadership in Pre-war Singapore) (Singapore, 1977), 79 . 
TABLE I

The Number of Different Types of Huiguan Established by the Major Dialect Groups in Various Periods from 1900 to 194 I

\begin{tabular}{rllll}
\hline $1900-10$ & $1911-20$ & $1921-29$ & $1930-3^{6}$ & $1937-41^{*}$ \\
\hline
\end{tabular}

a. Native place organizations

Hokkiens

Teochews

Cantonese

Hakkas

Hainanese

$\begin{array}{ll}2 & 2 \\ - & - \\ - & 3 \\ - & 1 \\ - & -\end{array}$

$\begin{array}{ll}2 & 4 \\ - & 2 \\ 3 & 2 \\ 1 & 1 \\ - & -\end{array}$

b. Clan associations

Hokkiens

Teochews

Cantonese

Hakkas

Hainanese

$\begin{array}{ll}2 & \text { I } \\ - & - \\ 2 & \text { I } \\ - & - \\ 3 & -\end{array}$

$\begin{array}{ccc}\text { I } & \text { I } & 3 \\ - & - & \text { I } \\ - & 3 & 2 \\ - & - & \text { I } \\ 3 & 6 & 7\end{array}$

c. Guilds

Hokkiens

Teochews

Cantonese

Hakkas

Hainanese

$\mathbf{1}$
5
-
-

Total:

20

17

6
3
3
-
-

$\begin{array}{ll}5 & 2 \\ - & 6 \\ 2 & 2 \\ - & 2 \\ 2 & 1\end{array}$

* The r 930 are divided arbitrarily into two periods to highlight the impact of both the Great Depression and the climax of the nationalist movement on huiguan formation. It should be noted that more than half of the 26 organizations founded between 1930 and 1936 were actually established after I 934 when the economy began to recover.

Sources: C. Gamba, 'Chinese Associations in Singapore,' Journal of the Malaysian Branch of the Royal Asiatic Society 39 (1966), I 23-68; W. Moese et al., Chinese Regionalism in West Malavsia and Singapore (Hamburg, 1979); Ngow Hua, Xinjiapo huazu huiguan zhi 3 vols (Singapore, 1975); Nanvang nianjian (Nanyang Yearbook) (Singapore, 1940); Xingzhou shinian (Sin Chew Jit Poh toth Anniversary Souvenir Magazine) (Singapore, 1940).

TABLE 2

Important Hokkien Native Place Organizations Founded in the Period 1900-1941.

\begin{tabular}{ll}
\hline Founding Year & \multicolumn{1}{c}{ Huiguan } \\
\hline 1918 & Chin Kang Hoey Kuan \\
1923 & Ann Kway Association \\
1923 & Hui Ann Association \\
1929 & Ho San Kong Hoe \\
1929 & Chang Chow General Association \\
1931 & Tung Ann District Guild \\
$193^{2}$ & Amoy Association \\
\hline
\end{tabular}

Sources: See Table I 
TABLE 3

Important Cantonese Native Place Organizations Founded in the Period 1900-194I.

\begin{tabular}{ll}
\hline Founding Year & \multicolumn{1}{c}{ Huiguan } \\
\hline I9I I & Zengyi Cishan Tang \\
I919 & Fa Yun Wui Kwan \\
I925 & Qingyuan Huiguan \\
$193^{\circ}$ & Chung San Lam Chan Thung Hiong Wui \\
1937 & Zhongshan Haizhou Tongxianghui \\
I937 & Sun Hing Hui Koon \\
I939 & Hok San Association \\
$194 \mathbf{I}$ & Zhongshan Guzhen Tongxianghui \\
I94I & Zhongshan Caobu Tongxianghui \\
\hline
\end{tabular}

Sources: See Table 1

TABLE 4

Hainanese Clan Associations Founded between 1900 and $194 I$.

\begin{tabular}{ll}
\hline Founding Year & \multicolumn{1}{c}{ Huiguan } \\
\hline 1900 & Han Shi Ci \\
1903 & Long Shi Ci \\
1910 & Heng Jai Wong Clan Association \\
1924 & Kiung Chow Leo Clan Association \\
1926 & Qiongya Wang Shi Ci \\
1926 & Keng Yai Choo Tee Clan \\
1935 & Kiung Jai Tan Clan Association \\
1935 & Kiung Jai Chow Say Kong Hai \\
1935 & Hoon Clan Association \\
1936 & Kiung Jai Koh Clan Association \\
1936 & Kiung Chow Goh Clan Association \\
1936 & Qiongya Zheng Shi Gonghui \\
1937 & Heng Jai Lim Clan Association \\
1938 & Kiung Jai Ong Clan Association \\
1939 & Qiongya Xie Shi Gonghui \\
1939 & Kheng Keow Heng Clan Association \\
1940 & Kiung Jai Lee Clan Association \\
1941 & Kheng Zi Yeo Clan Association \\
$?$ & Qiongya Zeng Shi Gonghui \\
\hline
\end{tabular}

Sources: See Table 1

While the more affluent Hokkien and Teochew communities tended to organize commercial guilds, the Cantonese ones were mainly made up of craftsmen, labourers and a smaller number of shopkeepers and traders (see Table 5 for some examples of Cantonese guilds). 
TABLE 5

Cantonese Guilds Established between 1900 and $194 I$.

\begin{tabular}{ll}
\hline Founding Year & \multicolumn{1}{c}{ Huiguan } \\
\hline 1906 & Guangbang Kezhan Hang \\
I 908 & Heng Woh Goldsmiths' Hong \\
I908 & Dried Goods Guild \\
I909 & Cantonese Pork Butchers' Guild \\
I910 & Kwong Pong Rattan Guild \\
I912 & Barbers' Association \\
I912 & Yit Chuen Printers' Association \\
I914 & Tong Lok Shoemakers' Hong \\
I923 & Xiangshan Xingchuan Guan \\
1929 & Gongshu Hang \\
1929 & Engineering Mechanics's Association \\
I929 & Jingshi Hang \\
I934 & Tushang Gonghui \\
1939 & Cantonese Cooked Food Sellers' Association \\
1939 & Kwong Foh Hong \\
\hline
\end{tabular}

Sources: See Table I

Theoretically speaking, all three organizational principles, i.e. surname, occupational and territorial identities, can be used for social formation beyond the rigid bang framework. There were a few cases of surname huiguan enroling members from more than one sub-ethnic group back in the late nineteenth century. ${ }^{16}$ After the turn of the century, the number of guilds and clan associations with multi-dialect group membership increased gradually. Towards the end of our period, there was even a Kwangtung Huay Kuan formed among the Teochews, Cantonese, Hainanese and Hakkas. ${ }^{17}$ Nevertheless, the impact of collaborative endeavour on the evolving bang-ridden community structure was at most peripheral. For one thing, the multibang nature of some of these organizations was nominal. This was especially the case of the guilds. As long as dialect group economic specialization persisted, it meant that the majority of trade, craft and labour guilds would remain bang bodies. An example was the Singapore Tea Traders' Association established in 1928. Eighteen of the twenty-two founding members were Hokkiens and fifteen of them

${ }^{16}$ One example was the Po Chiak Keng Tan Si Chong Su which began in 1878 as a Hokkien body. As early as $\mathbf{1 8 8}_{3}$, Teochews were accepted as members. Ngow Hua, Xinjiapo huazu huiguan zhi, vol. 2, 23-4.

17 NA Kwangtung Huay Kuan Minutes of Meetings of the Organizing Committee, 5 July r 938 . Also NYSP, 6 July $193^{8}$. 
came actually from Anxi. A similar case of domination by the Anxi people also existed in the Ngo Kim Kong Hoey of the hardware traders set up in $1936 .{ }^{18}$ For another, most large-scale multi-bang institutions continued to endorse the 'Thong Chai Formula' of proportional representation of bang in their internal structure. In other words, the legitimacy of the huiguan system and bang particularism was fully recognized and institutionalized. This was the case of the Kwangtung Huay Kuan which turned out to be a very limited and highly unstable alliance. The modus operandi was faithfully upheld in the Singapore Chinese Chamber of Commerce founded in 1906 and many other ad hoc committees overseeing the operation of community-wide charitable undertakings and later China-bound patriotic campaigns. Clamouring was heard for its abandonment and the obliteration of the larger bang system for the sake of community unity, but there was simply inadequate momentum to carry out the up-hill task of social restructuring and the transformation of consciousness. ${ }^{19}$

Also at work in organizational development was a process of conglomeration. A movement towards extra-territorial huiguan confederation first surfaced in the 1920 and developed from strength to strength in the late rg3os. There were numerous instances of individual regional institutions or entire bang headquarters seeking organizational connections with counterparts in various parts of British Malaya and in the Nanyang. In either case, the Hokkien organizations were pioneers. Their Eng Choon Huay Kuan joined the Xiamen-based Overseas Yongchun Federated Association in 1926 and served as its Nanyang head branch. This was followed by the Hui Ann and Ann Kway Associations which partook in their Malayan federations in I93 I and 1933 respectively. ${ }^{20}$ Moreover, several

18 Many contemporary observers and scholars have commented on the phenomenon of economic specialization or even monopolization by different subethnic groups. The best discussion to date is Cheng Lim-keak, Social Change and the Chinese in Singapore particularly chapter 5 . The examples cited here are from Xinjiapo anxi huiguan jinxi jinian tekan (Singapore Ann Kway Association 5oth Anniversary Souvenir) (Singapore, 1973), 357-8, 366-7.

19 Xinjiapo zhonghua zongshanghui gishiwu zhounian jinian tekan (Singapore Chinese Chamber of Commerce and Industry $75^{\text {th }}$ Anniversary Souvenir Issue) (Singapore, $1982), 56$. On the Kwangtung Huay Kuan and some isolated attempts on the part of a few reform-minded Chinese leaders to dismantle the rigid bang system, see Wing Chung Ng, 'Huiguan-Regional Institutions in the Development of Overseas Chinese

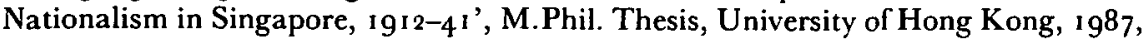
$187-9,228-41$.

${ }_{20}$ NYSP, 4 May 1928. Xingzhou huian gonghui wushi zhounian jinian tekan (Singapore Hui Ann Association 5oth Anniversary Souvenir) (Singapore, 1979), 85. NA Ann Kway Association Minutes of Meetings, 5 Feb. 1933. 
attempts at creating a Malaya-wide Hokkien confederation were made in the late 1920 s and early 1930 s, though no concrete result was achieved because of leadership conflicts and emergent financial difficulties. Eventually their Nanyang Hokkien General Association was established in Singapore in 1941 during a popular campaign to dislodge the corrupt Fujian provincial governor Chen Yi from power. ${ }^{21}$

The huiguan federation movement among the other sub-ethnic groups was largely taking place at the bang level. The Federation of Hainanese Associations in the British Territories of Nanyang was organized in I933 and the Federated Teochew Associations of Malaya in 1934. For the Hakkas, the setting up of their Nanyang Khek Community Guild in 1929 was initially an attempt at local bang consolidation and the enterprise developed only subsequently into a vigorous pursuit of Malaya-wide confederation..$^{22}$ As such, its early history belongs to the equally significant area of huiguan reform.

By huiguan reform, I do not mean a coherent and consistent blueprint of organizational reconstruction. Rather, I understand it as a loosely-defined set of reform measures advocated by many local leaders to enhance the viability of individual huiguan, or to revitalize dormant organizations, by bringing their raison d'être in line with the changing needs and aspirations of the community. There was no general consensus regarding which step should be taken at what time and to what extent, but several key items were often on the reform agendas. In the following examples we can observe some perceptible changes in functional emphases, a drastic revamping of the institutional structure and at some point, power struggles in the leadership.

To begin with, many Chinese huiguan underwent some kind of secularization. Unlike the situation in the nineteenth century, no more prominent temples were built by any dialect or regional group in this period. In fact, some native place associations tried earnestly to

${ }^{21}$ On these futile efforts, see the various issues in the NYSP in 1929, 1931 and 1932. The most prominent Hokkien leader, Tan Kah Kee, has given an incomplete and partisan account of the events in his autobiography Nanqiao huiyilu (Tan Kah Kee: An Autobiography) (Singapore, 1946; repr. Hong Kong, 1979), 37-40 passim. On the Nanyang Hokkien General Association, see NYSP, I-2 April 1941. Notice the reminiscences of Tan in his Nanqiao huiyilu, 230-79 as well.

22 Malaixiya xinjiapo qiongzhou huiguan lianhehui sishi zhounian jinian tekan (Malaysia and Singapore Federation of Hainanese Associations 4oth Anniversary Souvenir Magazine) (Johore, 1973), 10. NYSP, I6 Dec. 1933. Malaixiya chaozhou gonghui lianhehui di ershijiu zhounian jinian tekan (The Federated Teochew Associations of Malaysia 29th Anniversary Souvenir) (Singapore, 1964), 35-7. NA Nanyang Khek Community Guild Minutes of Meetings. Keshu zonghui shizhounian jinian tekan (Nanyang Khek Community Guild toth Anniversary Souvenir) (Singapore, n.d.). 
discard their previous religious image. The Hokkien bang headquarters, the Thian Hock Keng, was a case in point. Despite the founding of a formal Hokkien Huay Kuan inside the temple in 186o, the Hokkien bang centre remained known as the Thian Hock Keng in popular nomenclature well into the twentieth century. This became disagreeable when, as a result of changing social expectations and, perhaps, Christian influences, embracing a folk religion was no longer considered a respectable calling of a 'modern' social organization. As a matter of fact, the Huay Kuan had already suspended its sponsorship of the annual religious procession after the turn of the century. All 'superstitious' elements were deleted from its new constitution of I9I6. In the early I920s, the bang centre was moved into a new clubhouse to build up an independent physical identity from the yoke of the temple. ${ }^{23}$ In comparison, less drastic action was taken by the Hainanese to dissociate their Kiung Chow Hwee Kuan from the Tin Hou Kong. The two bodies continued to share the same premises, but the Hwee Kuan was officially registered under the Societies Ordinance in $193^{2}$, and became functionally and financially detached from the temple management. ${ }^{24}$

From a larger perspective secularization was just part of an ongoing process of functional redefinition in this period. There was certain continuity in the provision of local services. Some welfare undertakings of the huiguan expanded on the bases of their historical commitments. They had been pioneers in providing basic Chinese education for the young children in the community in the previous century; after igoo, not only did the number of schools directly run by these organizations increase, but they were among the major benefactors of some community-based enterprises such as the Chinese High School, which was one of the first institutes offering Chinese secondary education in the region. ${ }^{25}$ Another example of their local services

23 Song Ong Siang, One Hundred Years' History of the Chinese in Singapore (Singapore, 1923; reprinted 1984), 407-9. Ngow Hua, Xinjiapo huazu huiguan zhi, vol. I, 58. LP, 22 Jan. 1916. NYSP, 26 Nov. 1927 . We still lack a historical study of Christianity in the Chinese community in Singapore, though the above study of Song is full of scattered information. See also a pioneering treatment by Leung Yuan Sang, 'Zongjiao yu geming: xinjiapo huaren jidutu dui geming yuntong zhi fanying' (Religion and Revolution: the Response of the Chinese Christians in Singapore to the Revolutionary Movement), a paper presented at the Conference on the Nanyang Chinese and the Igi I Revolution, Taipei, Feb. I 986.

${ }^{24}$ Xinjiapo qiongzhou tianhougong qiongzhou huiguan dasha luocheng jinian tekan, 65 .

25 An early example of huiguan educational service was the Chong Boon School in the Thian Hock Keng in the mid Igth century. After I 9oo, important Chinese schools 
was the mushrooming of 'mutual aid' sections in many regional associations after the Great Depression. Apparently these new sections aimed at a better co-ordination of the existing welfare provisions and the promotion of a grass-roots collective effort at mutual assistance on occasions of financial, social and ritual needs, instead of relying solely on the organizations' corporate resources. ${ }^{26}$

In retrospect, historical continuity is less clear in huiguan activities regarding China and the native areas. It can be argued that a built-in function of these traditional organizations was to preserve, if not to promote, a remembrance of the native place and an active identification with the home territory. Nonetheless, a careful scrutiny of the Chinese nationalist movement in Singapore in the period leading up to and in the aftermath of the 19 i I Revolution reveals that the part played by the huiguan was only marginal. While some individual leaders were supporting the reformist or revolutionary causes, they by-passed these regional institutions and resorted to the reading rooms, partisan newspapers and party lodges as their bases of operation. At that time, the huiguan were simply not considered an appropriate channel of patriotic activism. ${ }^{27}$ As we are going to see, this situation changed drastically in the following decades.

In stark contrast to the earlier period, China-oriented engagements were the single-most important form of huiguan activism between the I920s and the early I 940 . The Chinese huiguan were the organizational backbone in many community-wide patriotic campaigns such as the fund-raising and anti-Japanese boycott movements after the Jinan Incident of May 1928 and the gigantic National Salvation

directly funded and/or managed by the bang centres were the Yingxin and Khee Fatt of the Hakkas, the Yeung Ching of the Cantonese, the Tuan Meng of the Teochews, the Tao Nan of the Hokkiens and the Yoke Eng of the Hainanese. Yong Ching-fatt, Zhangian xinghua shehui, 19 and his 'Daonan xuexiao zhi chuangban yu fazhan' (The Founding and Development of the Tao Nan School), SCJP, 28 June 1982 . On the Chinese High School, see Xinjiapo nanyang huaqiao zhongxue chuangxiao liushiwu zhounian jinian li quangqian xiansheng tongxiang jiemu jinian tekan (Souvenir Magazine on the Unveiling Ceremony of the Bust of the Late Datuk Lee Kong Chian in Commemoration of the 65th Anniversary of the Chinese High School) (Singapore, 1984-85).

${ }^{26}$ For individual examples, see the following: NYSP, 27 Feb. 1935, 4 June 1935, 25 Feb. 1937, 15 Dec. 1938, 4 March 1939; NA Nam Soon Wui Kuan Minutes of Meetings 14 May and 14 June 1941 .

${ }^{27}$ I relied mainly on the Lat Pau and the extremely well-documented study of Yen Ching-hwang, The Overseas Chinese and the iglt Revolution with Particular Reference to Malaya and Singapore (Kuala Lumpur, 1976). A similar conclusion can be deduced from negative evidence. Had there been an active participation on the part of any huiguan, it would have been eagerly publicized after $191 \mathrm{I}$. 
Movement in $1937-1941{ }^{28}$ In both cases, a campaign headquarters was organized which drew participants from all the bang centres. The latter were then responsible for the mobilization of the respective subethnic groups via their huiguan and leadership networks. The basic structural resemblance notwithstanding, the National Salvation Movement of the late 1930s was a much larger and more vigorous campaign in terms of the intensity, scope and duration of social mobilization. This partly reflected a deeper sense of national crisis. It was, furthermore, an unmistakable result of huiguan proliferation in the previous decades which furnished a more elaborate and better organized (see below) network for the engineering of such a massive social movement. ${ }^{29}$

In addition to collective endeavour, many Chinese associations found themselves individually engaged in some long-term and shortterm commitments to contribute to the socio-economic improvement and political stability of their specific home regions. For instance, from the mid-i 920 , the Kim Mui Hoey Kuan was virtually engulfed in a native place reconstruction movement. It raised funds for relief work and for the more general rehabilitation of the local society in Jinmen, which had been besieged by endemic banditry for years; it became a fairly regular petitioner to the district and provincial authorities complaining about official corruption, misrule, and sometimes, insufficient governance; and lastly, the Hoey Kuan took up the responsibility for financing a local school and a road construction project. ${ }^{30}$ Such sharply focused particularistic concerns of the

${ }^{28}$ Existing studies on these patriotic movements usually focus on the role of the Kuomintang agents and the local Communists. For example, Y. Akashi, 'The Nanyang Chinese Anti-Japanese and Boycott Movement 1908-1928', Joumal of the South Seas Society 23 (1968), 69-96 and his The Nanyang Chinese Anti-Japanese National Salvation Movement 1937-4I (Kansas, 1970). See also the following work of Stephen Leong, 'Sources, Agencies and Manifestations of Overseas Chinese Nationalism 1 937-194 I', Ph.D. Dissertation, University of California, Los Angeles, 1976; 'The KMT-CCP United Front in Malaya during the National Salvation Period I $937-4$ I', $^{\text {', }}$ Journal of Southeast Asian Studies 8 (1 977), 3 $3^{1-47}$ and 'The Malayan Overseas Chinese and the Sino-Japanese War 1937-194', ibid. ro (1979), 293-320. Only in an early article by Pang Wing Seng and the more recent work of Yong Ching-fatt on Tan Kah Kee do we have a glimpse of the significant part played by the Chinese huiguan. Pang, 'The Double-Seventh Incident 1937: Singapore Chinese Response to the Outbreak of the Sino-Japanese War', ibid. 4 (1973), 269-99 and Yong, Tan Kah-kee: The Making of an Overseas Chinese Legend (Singapore, 1987), 181-8, 201-24.

${ }_{29}$ On the organizational structure of both campaigns, see NYSP, i 8 May, 6 June and 20 Aug. 1928 as well as 16 and 18 Aug. 1937. Note also my discussion in 'Huiguan-Regional Institutions', 146-8, $172-4$.

${ }_{30}$ NYSP, 17 May 1926, 15 July 1926, 5 Feb. 1929, $15^{-1} 7$ May 1929. For a background discussion on the contributions of the overseas Hokkiens to social and 
HUIGUAN DEVELOPMENT IN SINGAPORE, I 900-4I 483

Chinese huiguan reached a climax during the Second Sino-Japanese War. When the southeastern coastal home regions of the overseas Chinese were devastated and occupied by the Japanese military, the Chinese in Singapore, as those in many other places, plunged into a desperate native place salvation movement. Innumerable relief committees sprang up in the huiguan and the various bang centres, and subsequently, many of them were totally immersed into China-related affairs. ${ }^{31}$ In this light, the enthusiastic sponsorship of Chinese education was more than a continuous dedication. Rather it was informed and propelled by a rising Chinese consciousness. The setting up of the mutual aid sections in many huiguan may have another meaning too: it was a small structural operation to spare the institutional nerve centre and corporate resources for the more important undertaking of channelling patriotic concerns into concrete actions.

The thoroughness and complexities of the functional reorientation of the regional institutions, as just highlighted, cannot be understood unless we also examine the related issues of huiguan reorganization and leadership changes. This is particularly necessary because a common historical portrayal of traditional social organizations in overseas Chinese communities is that before the Pacific War they were mostly under the firm control of the established elite, and there is little indication of fluidity in huiguan leadership. The case of the Chinese organizations in Singapore defies such simple characterization.

Given the momentum of change, it is not a coincidence that drastic huiguan reform and leadership turnover occurred in the ig2os. A few examples will help to illustrate this point. Again let us begin with the Kim Mui Hoey Kuan. We have mentioned slightly earlier its growing concerns for home district affairs. In fact, at the same time the Hoey Kuan was redefining its own mission through constitutional amendments. The main task was to cancel two items on the existing huiguan constitution which were considered obsolete by the majority of the current leaders and members. One of them stipulated that corporate funds could be used only for local purposes, which conflicted with the prevailing opinion that huiguan resources should be harnessed for native place welfare. The other one provided the Straits-born Baba Chinese with at least one-third of the membership on the standing committee, which was equally objectionable because the local-born

economic development in Fujian, see Lin Jinzhi and Zhuang Weiji (eds), Jindai huaqiao touzi guonei qiyeshi ziliao xuanji (fujian juan) (A History of Overseas Chinese Investment in China: Selected Materials on Fujian) (Fuzhou, 1985), 266-73.

${ }^{31} \mathrm{Ng}$, 'Huiguan-Regional Institutions', $180-91$. 
were generally more acculturated and they cared less about China. The episode probably entailed some kind of leadership struggle, for it took a few years before the agitation resulted in concrete changes, but our materials say no further on this. ${ }^{32}$

Fortunately, we do have some detailed information on the reform of a few other organizations, particularly those of the dialect group headquarters. We know, for instance, the power struggle going on in the Teochew and Hokkien bang centres. In both cases, the incumbents were Straits-born Chinese whose leadership was severely criticized as inattentive to the interests and aspirations of their communities. Public opinion and support were drummed up and, in the case of the Teochews, legal action was taken to dislodge them from power. In the end, both the Teochew Ngee Ann Kongsi and the Hokkien Huay Kuan were completely re-organized and fell firmly into the hands of the new elites, who were championing an active identification of the bang headquarters with public local interests as well as native place and Chinese affairs. ${ }^{33}$

The new organizational structure that emerged in the aftermath of the takeovers was indicative of increasing bang power and prestige. The Ngee Ann Kongsi remained an elitist body and served as the trustee of the Teochew community's public properties. Its membership, however, was expanded to include the cream of the Teochew commercial elite. On the popular front, the Teochew Poit-Ip Huay Kuan was founded to encourage mass participation. The Kongsi and the Huay Kuan shared the same premises and their constitutions provided enough interlocking of their executive committees to ensure a coherent and stable leadership. ${ }^{34}$ The internal set-up of the reformed Hokkien Huay Kuan was no less impressive. It had an enlarged power structure of some forty office-bearers and thus cast a wide net to draw participants from various prefectural and district huiguan. This turned the bang centre into no mere rallying point but an integrative mechanism for the Hokkien organizations. Other than this,

32 NYSP, 4 Feb. Ig29.

${ }^{33}$ On the Teochews, see Xinjiapo chaozhou bayi huiguan jinxi jinian kan (Singapore Teochew Poit-Ip Huay Kuan's Golden Anniversary Souvenir Publication) (Singapore, 1980), I 54. NA Ngee Ann Kongsi Rules of the Association 1933, 1 7-22. NYSP, 7 Jan. I 928 . On the Hokkiens, see NYSP, i 8 June 1927 , 1 I July i 927 , 22 July 1927,30 Jan 1929, 4 Feb. 1929, 6 March 1929, as well as the account of Yong Chingfatt, Tan kah-kee, 135-40.

${ }^{34}$ NA Ngee Ann Kongsi Rules of the Association, and Membership Register. Xinjiapo chaozhou bayi huiguan jinxi jinian kan, 298. Tan Too Hoe, 'The Chinese Associations in Singapore: A Case Study of Ngee Ann Kongsi and Teochew Poit-Ip Huay Kuan', B.S.S. Honours thesis, National University of Singapore, $1984,25-8,4^{\circ-2}$. 
the 'committee system' was adopted, which was a structural arrangement for social organizations advocated by the Chinese Nationalist Government after I928. Instead of lumping all the leaders into a board of directors with no role specification, the system could give each office holder a specific task and increase public accountability. ${ }^{35}$ (See Table 6 and Figure I)

With all the above organizational changes, it was not surprising that the Chinese huiguan were transformed from essentially mutual help establishments into versatile machinery for collective interest articulation and popular mobilization. The reform of the bang centres, in particular, enhanced group consciousness and solidarity, and the huiguan/bang system became an indispensable operational framework for any large-scale social campaign.

\section{Towards an Explanatory Model}

How are we going to account for such a complex process of organizational changes which had significant quantitative and qualitative dimensions? What kinds of social dynamics were involved? ${ }^{36}$ In probing these questions, I have concentrated on the larger and structural features of organizational metamorphoses such as segmentation, conglomeration, functional re-orientation, institutional reform and leadership replacement as discussed above. Likewise, the explanations that I am going to suggest are conceived in equally broad categories. This approach will inevitably leave out some intriguing issues such as the changing popularity of different organizational forms over time. Nor have I paid much attention to the details of inter- and intra-dialect group variations. Admittedly, these thorny questions are beyond the scope of this paper. On the other hand, such

${ }^{35}$ Xinjiapo fujian huiguan gaizuhou diyijie yian ji zhangmu baogao (Singapore Hokkien Huay Kuan Minutes of Meetings and Account Report, 1929-30). NYSP, 6 March 1929 .

${ }_{36}$ I am aware of some interesting studies pertaining to the perceived decline of the traditional social organizations as a result of 'modernizing' current in the post-Second World War era. Examples from Singapore scholarship are Cheng Lim-keak, Social Change and the Chinese; Thomas Tan, 'Political Modernization and the Traditional Chinese Voluntary Associations: A Singapore Case Study', Southeast Asian Joumal of Social Science I 3, 2 (1985), 67-79, and 'Voluntary Associations as a Model of Social Change' ibid. 14, 2 ( ( 986), 68-84. For a North American example, see Kuo Chia-ling, Social and Political Change in New York's Chinatown: The Role of Voluntary Associations (New York, 1977). My analytical focus is on the more positive side of organizational growth. 
TABLE 6

Important Office Holders of the Hokkien Huay Kuan and Their Own Regional Huiguan Bases 6.1930.

\begin{tabular}{ll}
\hline Huiguan & Names of the leaders \\
\hline Ann Kway Association & Lim Keng Lian \\
Chang Chow General Assn. & Lee Chin Tian \\
Chin Kang Hoey Kuan & Ang Poh Sit \\
& Chng Phee Tang \\
& Siaw Chee Lai \\
& Tan Ban Ann \\
Eng Choon Huay Kuan & Ong Shiang Tee \\
Hui Ann Association & Ho Yen Pen \\
Lam Ann Association & Chew Hean Swee \\
& Hau Say Huan \\
& Ong Kiat Soo \\
Tung Ann District Guild & Liong Sau San \\
& Yap Geok Twee \\
& Chiang Hsi Pu \\
\hline
\end{tabular}

Source: Xinjiapo fujian huiguan gaizuhou diyijie yian ji zhangmu baogao (Singapore Hokkien Huay Kuan Minutes of Meetings and Account Report, 1929-30).
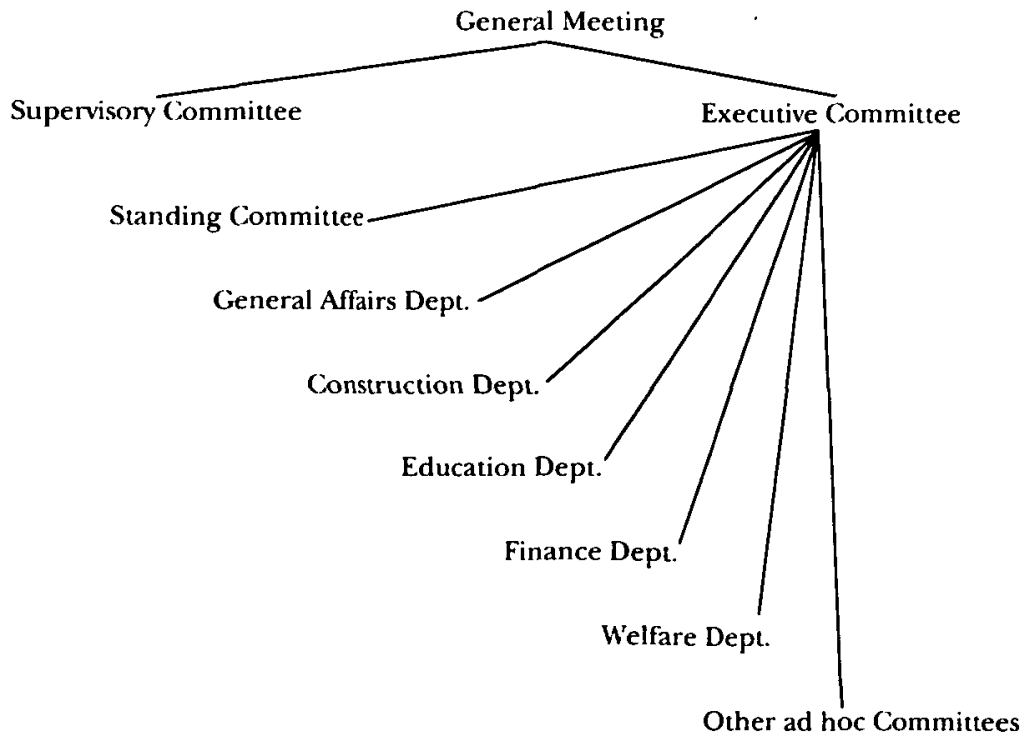

Fig. 1. The organizational structure of the reformed Hokkien Huay Kuan.

Source: see Table 6 . 
approach has the advantage of facilitating comparison across time and space. Scholars observing Chinese immigrant organizations in other historical contexts may find the following categories applicable to their studies. It is in this sense that I consider the discussion below with all its shortcomings as an analytical discourse 'towards an explanatory model'.

Let us start with the China factor, whose importance is most conspicuous in this study. From the discussion above, I doubt if it is necessary to dwell on this point at length other than recapturing two major themes. First, we can discern a close relationship between the upsurge of Chinese patriotic sentiments from the ig2os and the expansion of the organizational inventory. Many new associations and most of the huiguan federations were organized primarily for the purpose of contributing overseas Chinese efforts to native place reconstruction and later salvation. The Tung Ann District Guild, for example, actually grew out of a company formed among the Tongan natives to improve public transportation at home ${ }^{37}$ Deliberations at the meetings of the Teochew and Hainanese Federations were mostly about proposals for the betterment of the native areas. ${ }^{38}$ The spectacular increase in the number of huiguan between 1937 and 1941 can well be seen as fervent organizational expressions of localism and patriotism.

Second, in terms of manifest functions, the Chinese huiguan in Singapore underwent a re-orientation from local services to Chinabound concerns. By the second half of the rg2os, participation in native place- and China-oriented affairs had become the most popular and respectable form of social activism. These activities were new kinds of political rituals with important cultural and political meanings to the individual participants and tremendous implications for the involved social organizations. One good example is that the China factor had assumed immense moral power in leadership legitimation and de-legitimation. Anglicized Straits-born Chinese huiguan leaders were disgraced by a public alienation over their apparent lack of enthusiasm for China-related issues. Patriotism was then no longer

37 NA Tung Ann District Guild Minutes of Meetings 9 April r929. NYSP, 2 April I929, 9 July 1929 and 17 July 1929 . Lin Jinzhi and Zhuang Weiji (eds), Jindai huaqiao touzi, 324-7.

${ }^{38}$ Malaixiya chaozhou gonghui lianhehui di ershijiu zhounian jinian vekan, 38 . Xinjiapo chaozhou bayi huiguan jinxi jinian kan, 229. NYSP, 21 Aug. 1935, 27 March 1936, I April 1936, I July 1936, 17 Aug. 1936 and 21 Nov. 1936. Malaixiya xinjiapo qiongzhou huiguan lianhehui sishi zhounian jinian tekan, 10. NYSP, 30 Aug. 1934, 19 Jan. 1935, 28 July 1935 , 26 June 1936,4 Feb. 1937. 
just a desirable but an absolutely indispensable credential for any status and authority claimant. ${ }^{39}$

The second category consists of the influences of the host society on the development of immigrant associations. In some overseas Chinese contexts, the host government and the public were discriminating overtly against the Chinese. Given the opportunities, the latter usually organized themselves with a strong sense of seeking for mutual protection. ${ }^{40}$ The situation in Singapore was quite different. Racial prejudice was there in a multi-ethnic society, but two-thirds of the population were Chinese and their contributions to the local economy were widely recognized. Moreover, the British colonial administration was relatively paternalistic. Its policy towards the Chinese huiguan was indicative of its skills in political manipulation and its aim of social control. ${ }^{41}$

Earlier on, the British had realized the sub-ethnic divisions among the Chinese population, and had found the regional and clan organizations to be a much-needed supplement to their skeletal bureaucracy in ruling over such a linguistically diverse community. After the setting up of a Chinese Protectorate in 1877 , which later developed into the Secretariat for Chinese Affairs, the administration continued to rely on the Chinese organizations as a major channel of communication and social control. The huiguan were asked to disseminate official messages and to mediate in social conflicts and sometimes even personal disputes. This ruling strategy required an overall monitoring of their activities. They were requested to register themselves with the government, and to submit annually information such as the list of office-holders and members, and financial reports. In return, the cooperative organizations were officially recognized as representing the interests of their respective constituencies. The bang leadership, in particular, was honoured with prestige and a limited amount of deliberate authority, which came with an appointment to

39 Cf. Yong Ching-fatt, 'Leadership and Power in the Chinese Community of Singapore during the 1930s', Journal of Southeast Asian Studies 8 (1977), 195-209.

${ }^{40}$ This is a very common explanation for the origin and proliferation of Chinese organizations in pre-Pacific War North America, though in some literature the theme of institutional racism has been unduly emphasized. Compare, for instance, the general historical narratives in Liu Boji, Meiguo huaqiao yishi (An Anecdotal History of the Chinese in the United States of America) (Taipei, 1984), 265-304, and David Lee, Jianada huaqiao shi (A History of Chinese in Canada) (Taipei, 1967), 176-94, with the one-sided treatment of Peter Li, The Chinese in Canada (Toronto, I 988), 7 I-9.

${ }^{41}$ Cf. W. Willmott, The Political Structure of the Chinese Community in Cambodia (New York, 1970). 
sit on the Chinese Advisory Board. ${ }^{42}$ By the end of the late nineteenth century, the colonial government had established some kind of rapport with the huiguan.

This cordial relationship lingered on throughout the period of our study. The social and political utility of the huiguan did not diminish. They were counted upon in resolving conflicts of various scales, in soliciting public opinion and in drumming up mass support. For instance, the Hokkien Huay Kuan was highly praised by the Secretary for Chinese Affairs for its successful mediation in a violent confrontation among several Hokkien labour gangs in the early 1920s. ${ }^{43}$ On at least one occasion, the administration conducted an opinion poll among the huiguan when it was considering the possibility of enforcing compulsory registration of Chinese marriages and divorces. ${ }^{44}$ On the top of all these, the huiguan seem to have assumed an additional function, which was to provide a relatively moderate and accountable leadership in the escalating Chinese nationalist movement. The political activists such as the Malayan Communist Party and the local Kuomintang were eager to ride on the patriotic high tide to capture the popular mandate, but they were both strictly outlawed. ${ }^{45}$ The native place salvation and nationalistic enterprises of

42 There is no in-depth study on the government's policies towards the huiguan in the igth century. Nevertheless, the following references are generally useful: E. Thio, 'The Singapore Chinese Protectorate: Events and Conditions Leading to its Establishment 1823-77', Joumal of the South Seas Society (1 960), 40-80. Ng Siew Yoong, 'The Chinese Protectorate in Singapore', Joumal of Southeast Asian History 2 ( 1961 ), 89I 6 . R. N. Jackson, Pickering: Protector of Chinese (Kuala Lumpur, 1965).

${ }^{43}$ Annual Report 1922, Secretary for Chinese Affairs, 20. For the involvement of the huiguan in settling business and family disputes referred to them by the officials, see NA Ann Kway Association Minutes of Meetings 3 Nov. 1930, 16 Nov. 1932, 21 Feb. 1933 .

${ }_{44}$ Annual Report 1925, Secretary for Chinese Affairs, 41, and also various issues of NYSP from Sept. to Nov. 1925. The Chinese associations were also asked to organize community celebrations during festivals and visits of dignitaries from England. Xinjiapo zhonghua zongshanghui qishiwu zhounian jinian tekan, $67-82$ passim.

${ }_{45}$ On the fortune, or rather misfortune, of the Kuomintang in British Malaya, see the following: Yong Ching-fatt and R. B. McKenna, "The Kuomintang Movement in Malaya and Singapore 1912-1925', and 'The Kuomintang Movement in Malaya and Singapore 1925-1930', Joumal of Southeast Asian Studies $12(1981)$, I $_{18-1} 3^{2}$, and 15 ( 1984$), 91-107$; Ku Hung-ting, Kuomintang's Mass Movement and the Kreta Ayer Incident in Malaya 1927 (Singapore, I 976). The history of the communist movement in pre-war Malaya has received much less attention than the insurgency period after the war. Regarding published studies, we still have to rely on the dated accounts of G. Hanrahan, The Communist Struggle in Malaya (New York, 1954; reprinted 1971), Lucian Pye, Guerrilla Communism in Malaya: Its Social and Political Meanings (New Jersey, 1956), and Charles McLane, Soviet Strategies in Southeast Asia: An Exploration of Eastern Policy Under Lenin and Stalin (New Jersey, I966). Notice the careful study of Yeo 
the Chinese social organizations, on the other hand, were closely observed and yet tolerated. Hence the huiguan and the bang institutions were the officially sanctioned channels of patriotic expression. The China factor and the host government policy interacted in a way during the I 920 s and I 930 s that gave the huiguan an extremely opportune moment to proliferate.

Last but not least, the third category is the internal factors associated with the size and diversity of the community, and the pattern of leadership and authority. On this question, Maurice Freedman's general proposition can be our point of departure. In an influential article published thirty years ago, Freedman argued that at an early stage of immigration a small population and the relatively undifferentiated interests of a pioneering settlement meant that a few associations could serve their constituencies in various capacities. As the community increased in size and diversity, organizations proliferated and simultaneously developed into more specialized forms ${ }^{46}$ On the whole, our data from Singapore are in concordance with Freedman's arguments, though his model can be substantiated and improved on a number of points. ${ }^{47}$ The huiguan segmentation process in the first four decades of the twentieth century can be attributed, at least partly, to demographic forces. As the population of the various sub-ethnic groups expanded steadily, all of them experienced different degrees of organizational multiplication from a few prefectural huiguan or a single bang temple into a larger number of district, village, trade and craft associations. ${ }^{48}$ Here the simple logic seems to be: people organize themselves to meet various needs and on the basis of available resources. In this light, the roles of the elites are critical because they

Kim Wah, 'The Communist Challenge in the Malayan Labour Scene, Sept. 1936 Mar. I937', Journal of the Malaysian Branch of the Royal Asiatic Society 49 (1976), 36-79. Stephen Leong's discussions on both political parties in his dissertation are also very informed. Leong, 'Sources, Agencies and Manifestations'. On primary materials, see particularly the Monthly Review of Chinese Affairs furnished by the Secretary for Chinese Affairs between Oct. 1930 and Aug. 1938, which are in the British Government Archives $\mathrm{CO} 273$ series.

46 Freedman, 'Immigrants and Associations'.

47 For a brief debate on the validity of Freedman's proposition in the Chinese Canadian context, see E. Wickberg, 'Some Problems in Chinese Organizational Development in Canada, 1923-1937', and G. Baureiss's critique, 'Chinese Organizational Development-A Comment', Canadian Ethnic Studies I I (r979), 88-98 and 12 (1 980 ), 1 24-30.

${ }_{48}$ The total Chinese population increased from about 160,000 in 1901 to 600,000 in 194I, and the relative distribution of the various sub-ethnic groups remained fairly constant. Saw Swee Hock, Singapore Population, 57, and Nanyang nianjian (Nanyang Yearbook) (Singapore 1940), 45 . 
are the ones who possess the most resources (money, time and skills), and at the same time have a particular need for organizational life which brings leadership position and public recognition. In Singapore, we can trace the origin of many new huiguan in this period to the efforts of a group of enterprising individuals who were successful immigrant traders and shopkeepers in their thirties and forties. It was this generation of immigrant Chinese leaders who had the personal resources, social skills, ambitions for power and prestige, and enthusiasm for China-related issues that enabled them to engineer numerous huiguan reforms and topple the current leadership of the Straits-born Chinese. ${ }^{49}$

The above social dynamics associated with population growth and elite proliferation are commonly used to account for segmentation. Seldom have they been related to conglomeration in the literature. As a matter of fact, the availability of resources and leadership made the formation of a bang conglomerate or an extra-territorial confederation a feasible undertaking. Furthermore, a multiplicity of leaders helps to generate an elaborate organizational hierarchy as the most competitive and ambitious leaders strive for hegemony, thereby creating the need for high-level social organizations.

Finally, conflicts and competitions are something that can hardly be ignored in organizational circles. We have already talked about the power struggle between different generations of leaders embedded in huiguan reforms, but have said little about competitions within and among the different sub-ethnic groups and between leaders of the

49 See Chinben, 'Feilubin huaren wenhua de chixu' (Persistence and Preservation of Chinese Culture in the Philippines), Bulletin of the Institute of Ethnology Academia Sinica 42 (1976), 119-206. For years, the late Professor See has advocated the idea that traditional Chinese organizations proliferated in the post-war Philippines because there were more people aspiring to leadership status and influence. In our case a systematic study of Chinese huiguan leadership requires a separate book-length treatment. For biographical data in general, the huiguan publications are a very useful source of information. So far the work of local Chinese scholars has focused on the elites in the igth century. See Lim How Seng, Shile guji, Lim and Kua Bok Lim, Xinhua lishi yu renzu yanjiu (A History of the Chinese in Singapore and Biographical Studies) (Singapore, 1986). An exception is of course Yong Ching-fatt, now in Australia. Both his pioneering Zhanqian xinghua shehui and his biography of Tan Kah Kee have provided insights on some of the personalities and relevant issues. On the most notable Chinese leader, Tan Kah Kee, notice the publication industry on his career furnished by the mainland scholars. For example, Chen Bisheng and Yang Guozhen, Chen Jiageng zhuan.(A Biography of Tan Kah Kee) (Fuzhou, I981). Across the Taiwan Straits, there are also some useful biographical compilations. A recent one is published by the Huaqiao Xiehui Zonghui, Huaqiao mingren zhuan (Biographies of notable overseas Chinese) (Taipei, 1984 ). 
same generation. In a society where various levels of sub-ethnic identities prevailed, any kind of organizational activities would naturally be perceived as a demonstration of corporate consciousness, solidarity and prowess vis-à-vis the others. Conceivably it might also incite the others to follow. Take the extreme case of the Hokkiens. On the one hand, their numerical and economic strengths had given rise to the largest number of potential leaders, and had bred in-fighting among the Hokkien elite. On the other, considered as the most powerful bang, their huiguan were widely taken as the foremost targets in competition and standard of imitation. Any move on their part in terms of the founding of new huiguan, the confederation movement, functional expansion and so on would have a rippling effect on the society at large. ${ }^{50}$

\section{Some Reflections on the Study of Immigrant Organizations in Urban China}

To what extent is this overseas Chinese case study relevant to our understanding of urban corporatism in Chinese history? A meaningful and detailed comparison must await more scholarly efforts at research and discussion. But at a very general level, it seems to me that there are some revealing parallels and contrasts.

One interesting parallel is the important role played by the state in both contexts. In Singapore, as I have suggested, the colonial administration used the Chinese huiguan as a means of social control, and in the course of doing so, bestowed prestige, power and legitimacy on the organizations and leadership. In the study of urban China, the focus on the local bureaucratic establishment and its intention is even sharper because the history of huiguan is usually conceived within the matrix of state-society interaction. The following statement by Joseph Fewsmith is worthy to be quoted at length: ${ }^{51}$

the focus on interest groups (by which the author means various types of

so Partisan accounts such as the autobiography of Tan Kah Kee are an excellent source of information on these conflicts. Elsewhere I have attempted to put this issue and the details from Singapore in historical perspective. $\mathrm{Ng}$, 'Huiguan-Regional Institutions'. See particulariy ch. 7, 'The Disharmony of the Bang Society', in which I have examined systematically the personal rivalry between Tan Kah Kee and the Hakka magnate Aw Boon Haw, and its escalation into huiguan competition and Hokkien-Hakka animosity.

5) Fewsmith, Party, State, and Local Elites in Republican China: Merchant Organizations and Politics in Shanghai, 189o-1930 (Honolulu, 1985), 6. 
social organizations) provides a means of studying the changing relationship between state and society ... Existing on the boundary between state and society, interest groups reveal a great deal about the way in which societal interests are linked, suppressed, or circumscribed by the state. By examining such groups, we can see . . what interests are organized in and what interests are organized out. Intermediary associations provide a means to measure the degree to which state authority penetrates society and the extent to which the state confronts or co-opts local elites. Such organizations are also an indication of the level of bias of participation and hence an indirect measure of which interests or classes benefit from the regime.

However, such a strong focus on the state is illuminating only up to a point. The assumed activism of the state agency vis-à-vis the assumed passivism of the local elites and society is undoubtedly biased. In fact, scholars working within the framework of an authoritarian regime or 'oriental despotism' have long surmised that the underlying reasons for guild formation in urban China were to harness collective consciousness and prowess to minimize internal conflicts and to counteract official pressure. Nevertheless, they have unanimously posited that urban corporatism was underdeveloped because of the imbalance of power between the state and society. ${ }^{52}$ Only from some recent studies do we learn more about the emergence of the huiguan as a focal point of an extra-bureaucratic and genuinely community-based leadership, which was instrumental in altering the social, economic, cultural and political landscapes of urban China in the modern period. ${ }^{53}$ Oun appreciation of the resolve of urban communities and leadership to define issues, to claim local resources and to meet various domestic needs has barely begun.

In comparison, even more obscure is the native place connection as a factor in unleashing and shaping urban organizational changes in China proper. William Rowe has taught us about the deparochializa-

${ }^{52}$ See, for example, the historical account of D. J. Macgowan, 'Chinese Guilds or Chambers of Commerce and Trade Unions', Jourmal of the North China Branch of the Royal Asiatic Society 2 I (1886), 1 33-92; H. B. Morse, The Gilds of China, with an Account of the Gild Merchant or Co-hong of Canton (London, I gog); J. Burgess, The Guilds of Peking (New York, 1928); Quan Hansheng, Zhongguo hanghui zhidushi (A History of the Chinese Guild System) (Shanghai, 1935; repr. Taipei, 1978); and E. Balazs, Chinese Civilization and Bureaucracy: Variations on a Theme (New Haven, 1964), esp. 33, 41-4.

${ }^{53}$ I am referring particularly to the work of Rowe, Hankow: Commerce and Society, Hankow: Conflict and Community, and most recently 'The Public Sphere in Modern China', Modern China 16, 3 ( 1990), 309-29. See also Susan Mann, Local Merchants and the Chinese Bureaucracy $175^{\circ}$ to $195^{\circ}$ (Stanford, 1987), especially her ideas on merchant liturgies, and the built-in tensions and complications in any form of tax brokerage; Mary Rankin, Elile Activism and Political Transformation in China: Zhejiang Province, $1865-$ IgII (Stanford, I986); and David Strand, Rickshaw Beijing: City People and Politics in the Ig20s (Berkeley, 1989). 
tion of huiguan in terms of less exclusive membership requirement and more commitment to serve the local society. All these marked the emergence of a new urban-based consciousness and identity. ${ }^{54}$ But in light of our Singapore case study, we should ask the following as well: to what extent did the huiguan furnish a mechanism for some urban residents to be involved in distant home area affairs? More importantly, in what way did native place issues affect the social organizations, politics and general well-being of the immigrant communities?

Lastly, although the concept of bang has been applied to the study of Chinese society at home and abroad, we seem to have a clearer picture of organizational clustering and networking among the overseas Chinese. In Singapore, the dialect group headquarters commanded considerable respect and power not just because of the sheer wealth and prestige of the leaders. It was a reflection of a wellintegrated social group based on webs of personal ties, organizational connections, shared economic interests and a moral consensus. In China, we are fairly informed about the historical formation of bang among the sojourning merchants, craftsmen and labour gangs. Nevertheless, the local organizational scene tends to convey a general impression of relative disconnectedness and cellularity. ${ }^{55}$ For instance, we know very little about the relationship between the larger prefectural or provincial huiguan and the lesser regional, clan and labour organizations in the same area. Whether this reflects a basic difference between developments in China and overseas, or it is just a result of different research agendas among scholars can only be determined by more in-depth and comparative studies.

\footnotetext{
54 This theme is central to both volumes of his study but note particularly Hankow: Commerce and Society, $213-51,276-84,318-20$.

${ }^{55}$ See, for example, the work of Susan Mann Jones, William Rowe and a recent review by K. C. Liu, 'Chinese Merchant Guilds: An Historical Inquiry', Pacific Historical Review 57.1 (1988), I-23. Primary materials such as inscription data on the Chinese huiguan or the decennial reports (1882-1891, 1892-1901) of the Inspectorate General of Customs in Shanghai give the same impression. Some notable published collections of inscription materials are: Jiangsu Provincial Museum (comp.), Jiangsu sheng mingqing yilai beike ziliao xuanzhi (A Collection of Ming, Qing and Twentieth Century Stone Inscriptions from Jiangsu Province) (Jiangsu, I959); Niida Noboru, Pekin kosho girudo shiryoshu (Resource Materials on Industrial and Commercial Guilds of Beijing) 6 vols (Tokyo, 1975-83); Li Hua (ed.), Mingqing yilai beijing gongshang huiguan beike xuanbian (Selected Stele Inscriptions from Commercial and Handicraft Guilds in Beijing since the Ming and Qing) (Beijing, 1980); Shanghai Museum (comp.), Shanghai beike ziliao xuanzhi (A Selected Collection of Shanghai Inscriptions) (Shanghai, 1980); and Suzhou History Museum, Departments of History, Jiangsu Normal College and Nanjing University (comp.), Mingqing suzhou gongshangye beike (A Collection of Inscriptions of Suzhou Guilds in the Ming and Qing Periods) (Jiangsu, 198 I).
} 